\title{
Improved Performance Characteristics Using Double Layer Stacked Microstrip Loop Shaped Patch Structures for X-Band Operation
}

\author{
Deepanshu Kaushal $^{\mathrm{a}}$, T. Shanmuganantham* \\ ${ }^{a, *}$ Dept. of Electronics Engg, Pondicherry University, Pondicherry-605014 India
}

Received: 17 March 2017; Accepted: 06 August 2017; Published: 08 January 2018

\begin{abstract}
The design of a double layer stacked microstrip loop shaped patch antenna for multiband operation has been proposed. The design has been evolved following the iterations of a rectangular patch and a single layer loop patch structure. The material considered for the substrate of both the layers is $1.6 \mathrm{~mm}$ thick FR4 epoxy and the feeding technique used for the bottom patch is coaxial/ probe feed. The radiations from the bottom layer patch have been electromagnetically coupled to the upper layer patch. The main results including the reflection coefficient, bandwidth, radiation pattern, gain, directivity and VSWR for single frequency operation in each case have been discussed separately and finally compared. The comparison shows that the proposed stacked structure is clearly advantageous over the conventional rectangular patch and the single layer designed prototype in terms of the standard parameters that have been obtained. The three stage designs are useful to serve the X-band aviation applications including radio location and fixed mobile radio location.
\end{abstract}

Index Terms: Double Layered, Single Layer, Loop shaped patch antenna, Radio Location, Fixed mobile radio location.

(C) 2018 Published by MECS Publisher. Selection and/or peer review under responsibility of the Research Association of Modern Education and Computer Science

\section{Introduction}

The field of antenna technology has witnessed the proliferation of microstrip patch antennas that are not just being used for a wide variety of applications but have also attracted much of the research interest. Despite the several offered advantages including light weight, low profile, small size, compatibility and conformability, the conventional microstrip patch structures suffer from issues of narrow bandwidth. Studies have suggested that an improved bandwidth performance might result on the use of thick substrates [1] but at a cost of degraded

* Corresponding author. Tel.: +91 9486640168

E-mail address: shanmuga.dee@pondiuni.edu.in 
radiation characteristics and poor radiation efficiency. Other techniques to resolve the issue include the use of reactive loading [2], coupled resonators [3] and resonator apertures [4]. The concept of stacking patches is based on electromagnetic coupling and provides the much required enhancement of bandwidth. A stacked dualpatch electromagnetically coupled microstrip antenna as shown in figure 1 uses a radiating patch at the top and a feeding patch at the bottom.

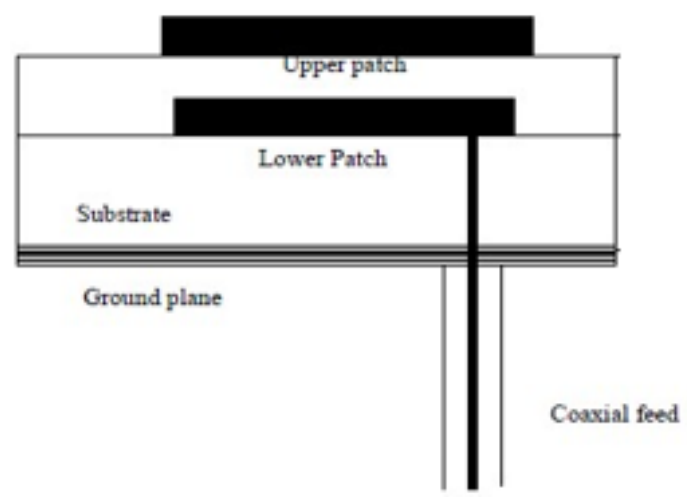

Fig.1. Stacked microstrip patch Configuration

In [5], T. Shanmuganantham proposed an implantable monopole $\mathrm{H}$-shaped antenna that offered a bandwidth of $180 \mathrm{MHz}$ for ISM applications. Another implantable Z-monopole antenna proposed by $\mathrm{T}$. Shanmuganantham in [6] offered a bandwidth less than $250 \mathrm{MHz}$ for different cases of patch. The danger patch antenna proposed by Deepanshu Kaushal in [7] achieved a maximum bandwidth of $12 \mathrm{MHz}$ for satellite applications. The microstrip cat patch antenna designed by T. Shanmuganantham in [8] offers a bandwidth of $370 \mathrm{MHz}$ for radio location purpose. In the clover slot patch antenna proposed by T. Shanmuganantham in [9] for biomedical applications, the bandwidth achieved was $180 \mathrm{MHz}$.

A double layer stacked microstrip loop shaped patch structure using FR4 epoxy [10] material for the substrates of both the layers and a coaxial feed at the bottom layer patch has been proposed. The radiations fed to the bottom layer patch through the coaxial feed [11] are electromagnetically coupled to the upper layer patch. The comparison of results of different stages show that the stacked loop structure at the third stage achieves a bandwidth improved by a factor of $43.3 \%$ over the single layer loop patch structure and that by a factor of $138.8 \%$ over the conventional rectangular patch. The stacked loop patch structure may thus be viewed to offer improved performance over the conventional rectangular patch antenna and the single layer microstrip loop patch antenna. The three stage designs may be used to serve the X-band aviation applications including radio location and fixed mobile radio location.

The section I of the paper gives a brief introduction to the microstrip patch structures and the stacked microstrip patch structures. The different existing works available in literature are included. The section II of the paper discusses the stacked loop patch antenna configuration through iterations of a rectangular patch and a single layer loop patch structure. The section III gives the parametric analysis while the section IV includes the discussion of results.

\section{Proposed Antenna Configuation}

The work proposes the design of a stacked (double layer) microstrip loop structure through a three stage iteration process. The stage I designs a conventional rectangular microstrip antenna followed by the design of a 
single layer loop patch antenna in stage II. The stage III finally develops a stacked (double layer) loop patch structure. The substrate used for the three design stages is $38 \mathrm{~mm}$ x $43.5 \mathrm{~mm}$ x $1.6 \mathrm{~mm}$ FR4 epoxy. The lower patch has been coaxially fed while the radiations from the lower patch have been electromagnetically coupled to the patch of the top layer.

\subsection{Iteration 1: Rectangular Patch}

The figure 2 shows a $38 \mathrm{~mm}$ x $43.5 \mathrm{~mm}$ microstrip rectangular patch (red) antenna that was developed using a $38 \mathrm{~mm}$ x $43.5 \mathrm{~mm}$ x $1.6 \mathrm{~mm}$ FR4 epoxy substrate (blue) of relative permittivity 4.4 and dielectric loss tangent 0.02. Coaxial feeding has been employed.

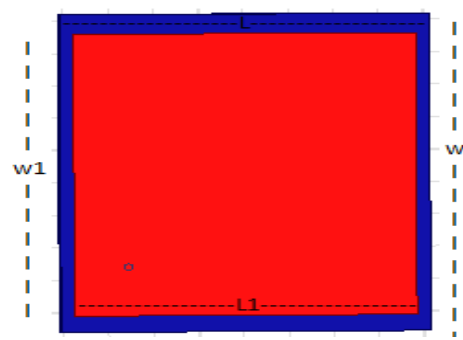

Fig.2. Designed conventional rectangular patch Antenna

The specifications of the designed conventional rectangular patch antenna are tabulated as under.

Table 1. Specifications of the designed conventional Rectangular Patch Antenna

\begin{tabular}{ll}
\hline Parameter & Value $(\mathrm{mm})$ \\
\hline L & 38 \\
W & 43.5 \\
L1 & 38 \\
W1 & 43.5 \\
\hline
\end{tabular}

\subsection{Iteration 2: Single Layer Loop Shaped Patch}

The second stage develops a loop shaped patch over a $38 \mathrm{~mm}$ x $43.5 \mathrm{~mm}$ FR4 epoxy substrate. The loop patch has been formed by subtraction of circles of appropriate radii. The dimensions of the developed structure are tabulated under.

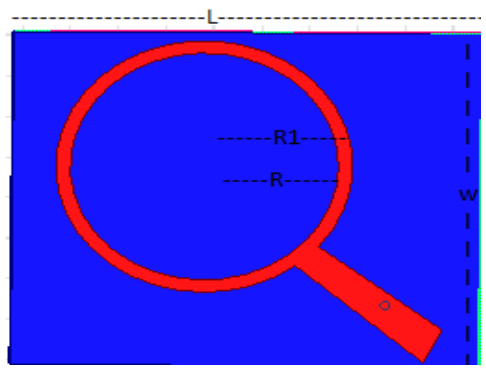

Fig.3. Proposed Loop patch Antenna 
Shaped Patch Structures for X-Band Operation

Table 2. Dimensions of the proposed single layer and dual layer stacked Loop Patch Antenna

\begin{tabular}{ll}
\hline Parameter & Value $(\mathrm{mm})$ \\
\hline $\mathrm{L}$ & 38 \\
$\mathrm{~W}$ & 43.5 \\
$\mathrm{R}$ & 14 \\
$\mathrm{R} 1$ & 15.5 \\
\end{tabular}

\subsection{Iteration 3: Double Layered Stacked Loop Structure}

A double layer stacked patch antenna is formed with the feed loop patch using a FR4 epoxy substrate and coaxial feeding. The radiating loop patch is a replica of the feed patch and both the patches are separated by FR4 substrate of $1.6 \mathrm{~mm}$ thickness. Electromagnetic coupling is used to excite the top element through the lower patch element that is located close to the ground and is fed using coaxial connector. The specifications for each of patch antenna is identical and correspond to that in table 2.

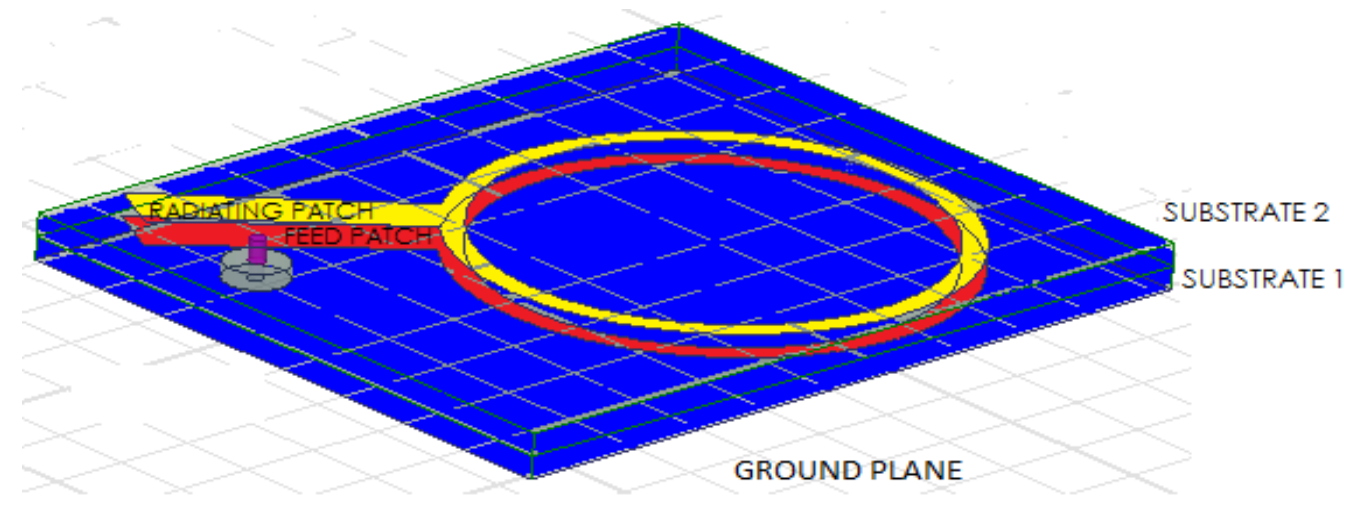

Fig.4. Proposed stacked Loop patch Antenna

\section{Study of Parameters}

Each of the proposed design stage uses a FR4 epoxy substrate that has a relative permittivity valued at 4.4 and dielectric loss tangent valued at 0.02. Coaxial coupling is used. In the third stage, the radiating patch at the top is electromagnetically fed via the feed patch at the bottom that uses a coaxial feed. Ground plane is used only by the bottom patch. The simulation software used is HFSS v-15 [12]. The three designs have been analyzed for their reflection coefficients, bandwidth, radiation pattern, gain, directivity and VSWR. Finally, the results have been compared.

\section{Results and Discussion}

The following section discusses the standard result parameters (reflection coefficient, bandwidth, radiation pattern, gain, directivity and VSWR) of the three design stages. The comparison of the results of the design stages has been done both graphically as well as in a tabulated manner. 


\subsection{Reflection Coefficient and Bandwidth}

The following comparative reflection coefficient [13] plot shows that the initially designed rectangular patch attains a reflection coefficient of $-10.15 \mathrm{~dB}$ at $9.92 \mathrm{GHz}$ with a bandwidth [14] of $180 \mathrm{MHz}$, the single layer loop patch achieves reflection coefficient of $-21.55 \mathrm{~dB}$ and bandwidth of $300 \mathrm{MHz}$ at $10.52 \mathrm{GHz}$ and the double layer stacked loop structure achieves a reflection coefficient of $-42.13 \mathrm{~dB}$ and a bandwidth of $430 \mathrm{MHz}$. Thus, a significant improvement of reflection coefficient and bandwidth parameters is observed at each subsequent design stage with the stacked geometry offering significantly enhanced parametric performance.

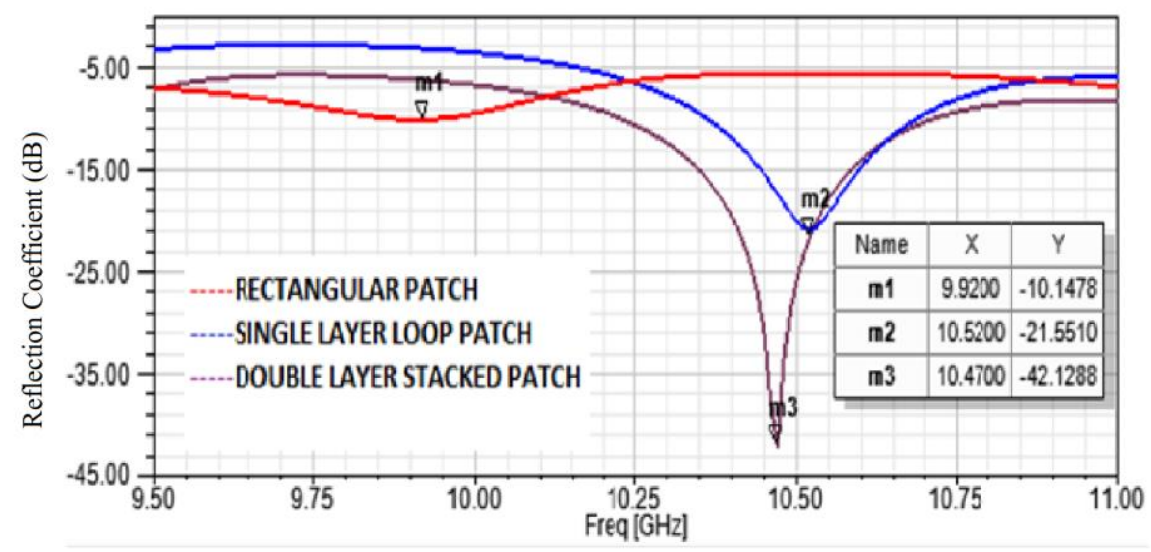

Fig.5. Reflection Coefficient plot for initially designed rectangular patch antenna

\subsection{Radiation Pattern and Gain}

The figure 6 shows the three dimensional radiation pattern [15] plot for the designed RMPA that achieves a maximum gain of $6.6 \mathrm{dBi}$ at $9.92 \mathrm{GHz}$.
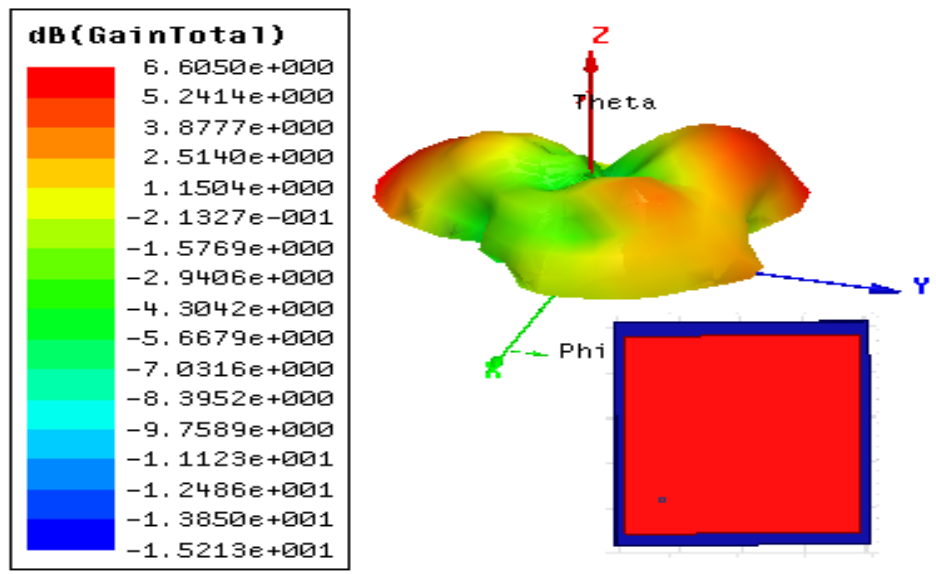

Fig.6. Radiation pattern plot for initially designed RPA 
The figure 7 shows the radiation pattern plot for the proposed single layer loop patch antenna indicating a gain of $9.67 \mathrm{dBi}$ at $10.52 \mathrm{GHz}$.
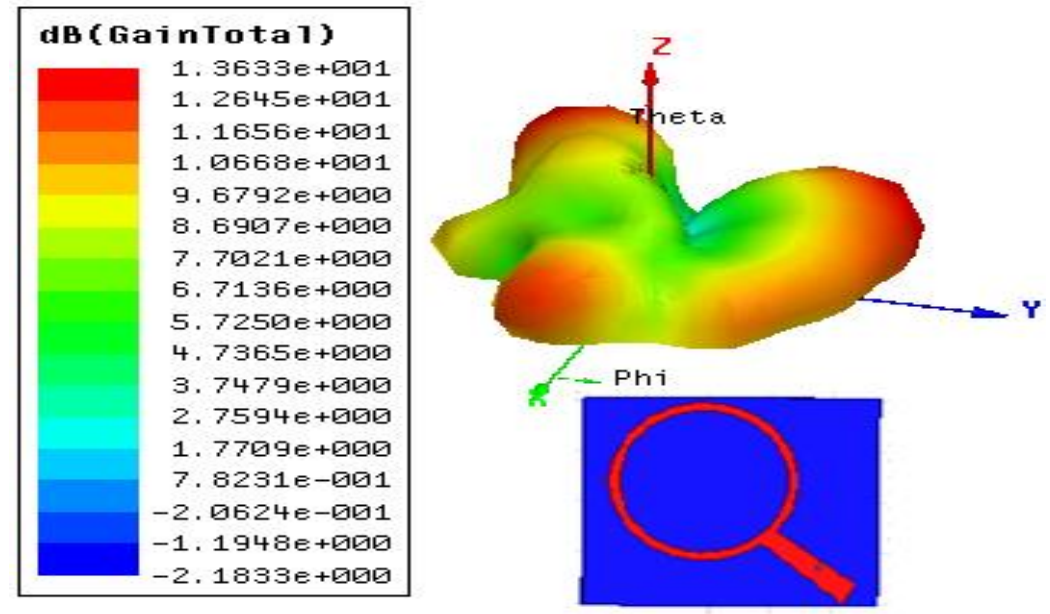

Fig.7. Radiation pattern plot for proposed Loop patch antenna

The figure 8 indicates a peak gain of $9.9 \mathrm{dBi}$ achieved at $10.47 \mathrm{GHz}$ for the proposed stacked loop structure.

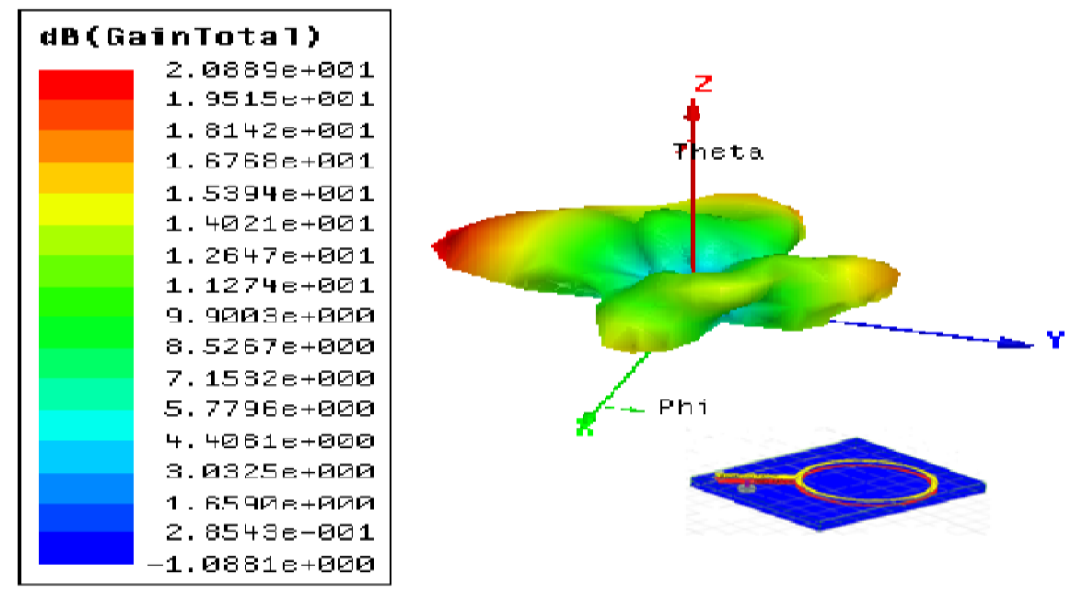

Fig.8. Radiation pattern plot for proposed stacked Loop patch antenna

Thus, it may be observed that a miniaturized loop patch geometry offers a significant improvement in gain at the resonant frequency when compared to the conventional rectangular patch. Stacking that results in a double layer structure witnesses a still higher resultant gain.

\subsection{Directivity}

The figures 9, 10 and 11 indicate the directivity [16] plots for RPA, single layer loop patch and the double layer stacked loop patch respectively. 


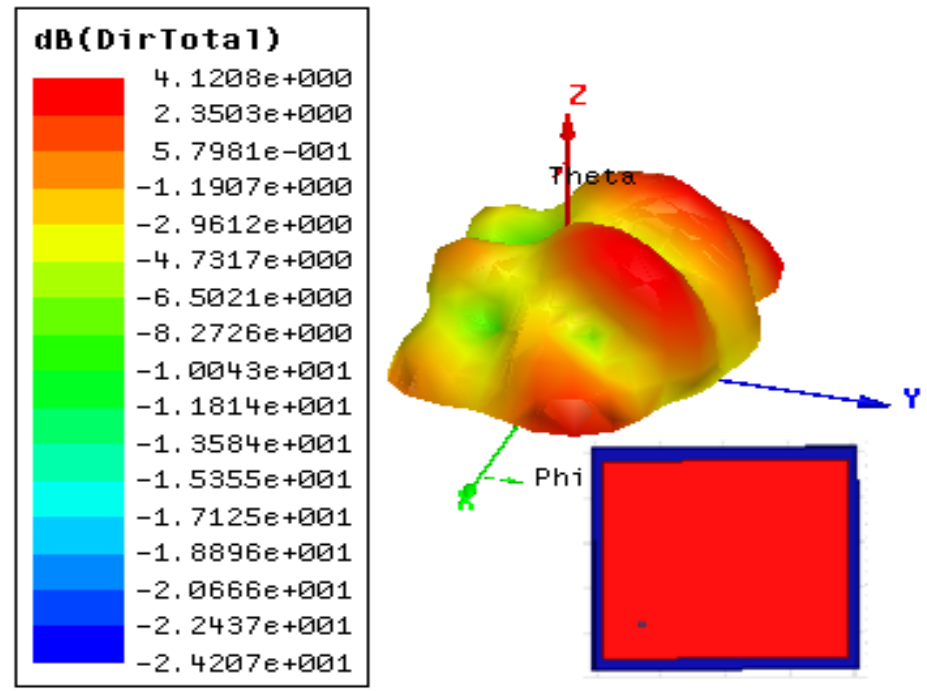

Fig.9. Directivity plot for initially designed rectangular patch antenna

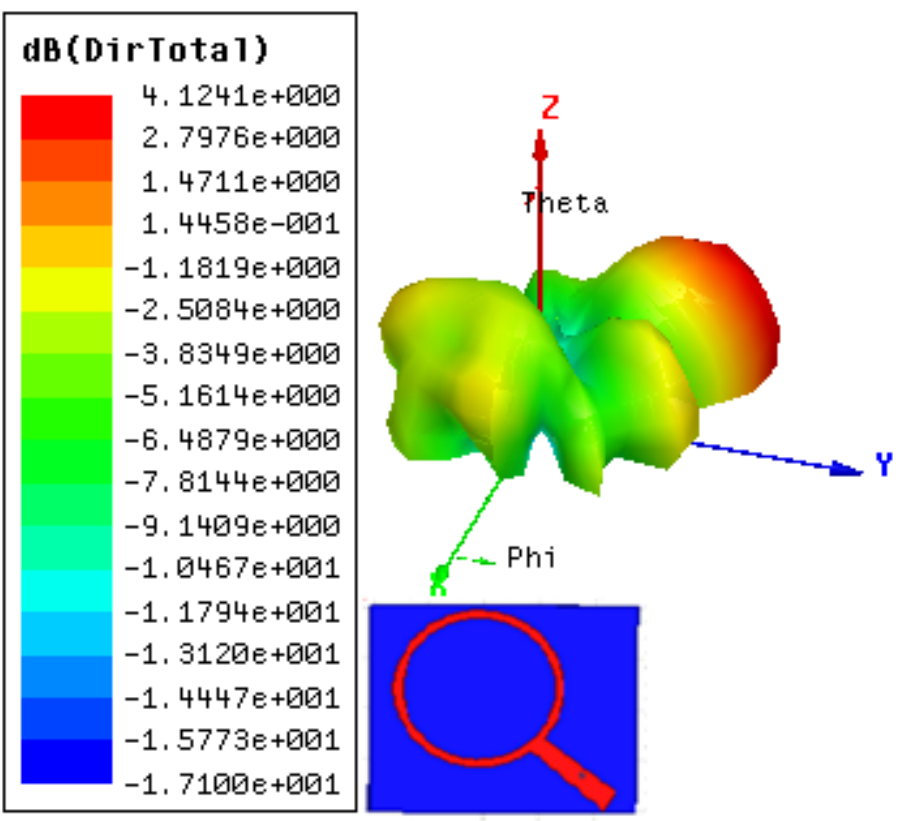

Fig.10. Directivity plot for single layer loop patch antenna 


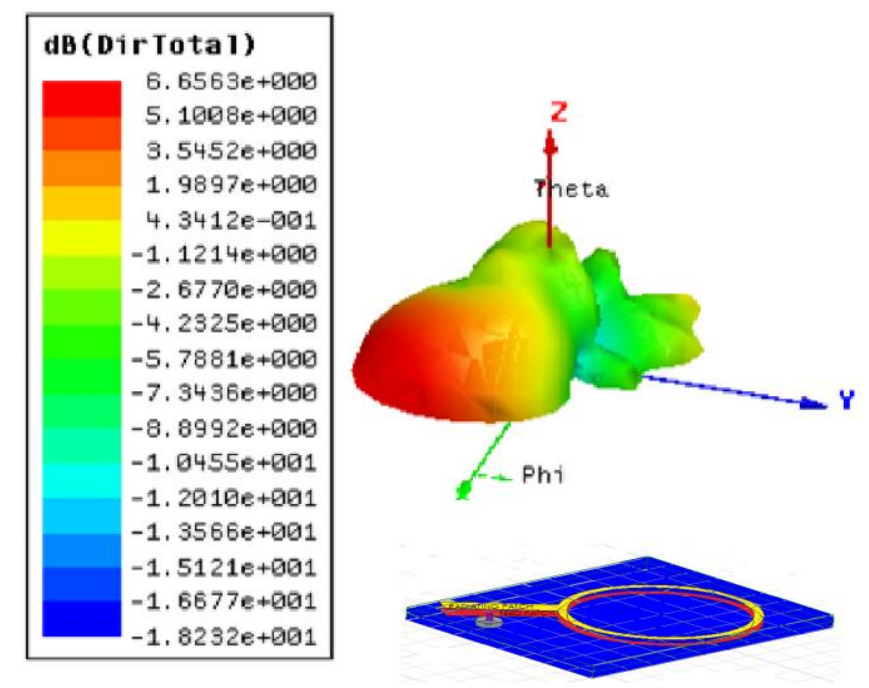

Fig.11. Directivity plot for double layer stacked loop patch antenna

The maximum directivity achieved in case of RPA at $9.92 \mathrm{GHz}$ is $5.79 \mathrm{~dB}, 4.12 \mathrm{~dB}$ at $10.52 \mathrm{GHz}$ in case of single layer loop patch antenna and $6.66 \mathrm{~dB}$ at $10.47 \mathrm{GHz}$ for double layer stacked loop patch antenna. Significant improvement in the directivity is recorded at each design stage. The stacked geometry offers a significantly improved directivity that is highest of all the stages.

\subsection{VSWR}

The figure 12 indicates a VSWR [17] of 1.902 achieved at $9.92 \mathrm{GHz}$ for the case of rectangular patch antenna, 1.199 at $10.52 \mathrm{GHz}$ for the case of single layer loop patch and 1.01 at $10.47 \mathrm{GHz}$ for the case of double layer stacked structure.

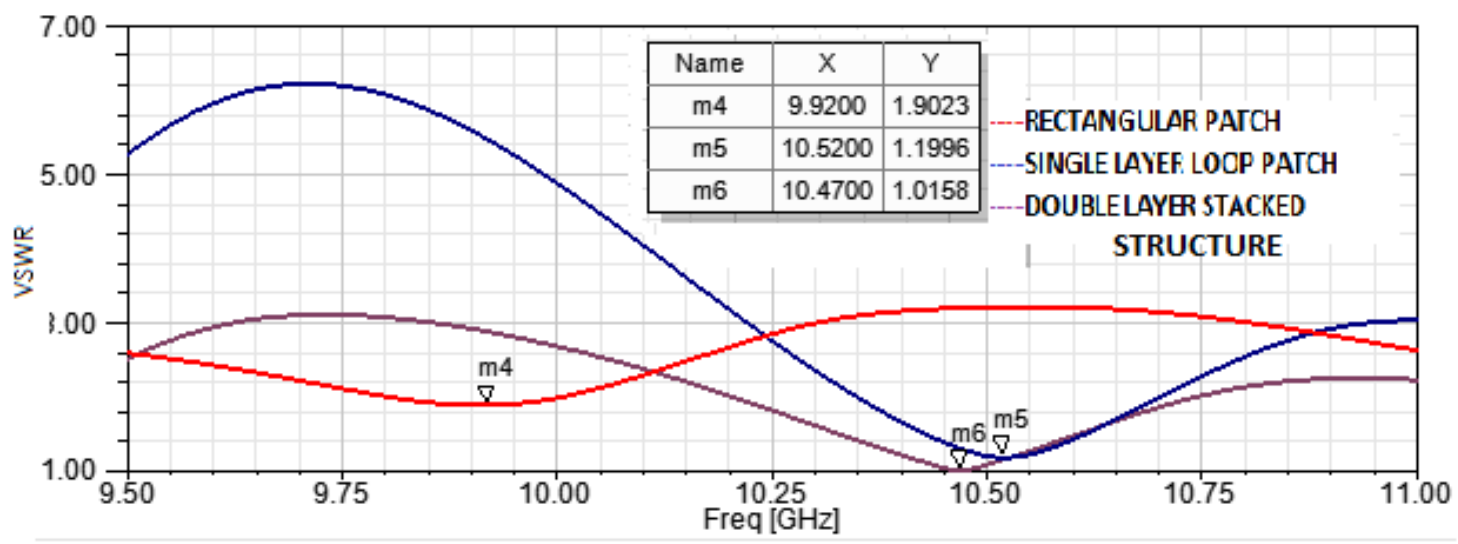

Fig.12. VSWR plot for initially designed rectangular patch antenna 
Thus, all the design stages of a microstrip stacked loop patch structure satisfy the condition that value of VSWR should lie between 1 and 2. The following table indicates a comparison of results obtained for the three design stages.

Table 3. Comparison of Results

\begin{tabular}{|c|c|c|c|c|c|c|}
\hline Proposed Design Stage & $\begin{array}{l}\text { Operating } \\
\text { Frequency } \\
(\mathrm{GHz})\end{array}$ & $\begin{array}{l}\text { Reflection } \\
\text { Coefficient (dB) }\end{array}$ & $\begin{array}{l}\text { Bandwidth } \\
\text { (MHz) }\end{array}$ & Gain (dBi) & $\begin{array}{l}\text { Directivity } \\
(\mathrm{dB})\end{array}$ & VSWR \\
\hline I: Rectangular patch antenna & 9.92 & -10.15 & 180 & 6.6 & 5.79 & 1.90 \\
\hline II: Single Layer Loop patch & 10.45 & -21.55 & 300 & 9.6 & 4.12 & 1.19 \\
\hline $\begin{array}{l}\text { antenna } \\
\text { III: Stacked Loop patch antenna }\end{array}$ & 10.47 & -42.13 & 430 & 9.9 & 6.56 & 1.02 \\
\hline
\end{tabular}

The results clearly indicate the improved performance characteristics of the stacked loop structure over the rectangular patch structure and the single layer patch structure. All the three designed prototypes may be used for radio location and fixed mobile radio location applications depending on their centre frequencies.

\section{Conclusions}

The design of a stacked dual layer loop patch antenna through iterations of a conventional RMPA and a single layer loop patch structure using coaxial feed for the feed patch and electromagnetic coupling for the radiating patch. The substrate used for both the patches is FR4 epoxy substrate that has a relative permittivity valued at 4.4 and dielectric loss tangent valued at 0.02. Significant characteristics including reflection coefficient of $-42.13 \mathrm{~dB}$, bandwidth of $430 \mathrm{MHz}$, gain of $9.9 \mathrm{dBi}$, directivity of $6.56 \mathrm{~dB}$ and a VSWR of 1.02 were obtained for the proposed stacked double layer loop patch structure which are higher than those obtained for the initially designed stages of the rectangular microstrip patch antenna and the single layer loop patch antenna. The stacked patch structure, thus, offers an improved parametric performance in terms of reflection coefficient, bandwidth, gain, directivity and VSWR than the preceding stages of conventional rectangular patch and the single layer loop patch antenna.

\section{References}

[1] Chen, W., Lee, K.F., and Lee, R.Q. Input impedance of coaxially fed rectangular microstrip antenna on electrically thick substrate. Microw. Opt. Technol. Lett., 1993, 6, (6), pp. 387-390.

[2] Rushit D Trivedi,Khagindra K Soo,Rajeev Jyoti. Cavity backed slot antenna. IJ-CA-ETS journal, vol 2, pp 23-26.

[3] Nakano, H., and Vichien, K. Dual-frequency square patch antenna with a rectangular notch. Electron Lett., 1989, 25, (16), pp. 1067-1068.

[4] Croq, F., and Pozar, D.M. Multifrequency operation of microstrip antennas using aperture coupled parallel resonators. IEEE Trans..Antennas Propag., 1992, 40, (11), pp. 1367-1374.

[5] S. Ashok Kumar, T. Shanmuganantham. Implantable CPW-Fed Monopole H-slot Antenna for $2.45 \mathrm{GHz}$ ISM Band Applications. AEU: International Journal of Electronics and Communication (IJEC- Elsevier), vol. 68, no.7, pp.661-666, July 2014.

[6] S. Ashok Kumar, T. Shanmuganantham. CPW-Fed Implantable Z-Monopole Antennas for ISM Band Biomedical Applications. EuMA International Journal of Microwaves and Wireless Technologies 
(IJMWT), Cambridge University, pp. 1-6, July 2014.

[7] Deepanshu Kaushal, T. Shanmuganantham, "Danger Microstrip Patch Antenna for Fixed Satellite Applications", IEEE International Conference on Emerging Trends in Technology (ICETT), 2016.

[8] T. Shanmuganantham, Design of Single Band Microstrip Cat Patch Antenna for Radio location. International Conference on Antenna Test \& Measurement Society (ATMS), Hyderabad, 2017.

[9] S. Ashok Kumar and T. Shanmuganantham. Design of Clover slot antenna for biomedical applications. Alexandria Engineering Journal, pp. 1-5, 2016.

[10] Deepanshu Kaushal, T. Shanmuganantham, "A Vinayak Slotted Rectangular Microstrip Patch Antenna Design for C-Band Applications”, John Wiley-Microwave and Optical Technology Letters, 59(8), pp. 1833-1837, August, 2017.

[11] Deepanshu Kaushal, T. Shanmuganantham, "Design of a Compact and Novel Microstrip Patch Antenna for Multiband Satellite Applications", Journal of Materials Today: Elsevier, In Press.

[12] Deepanshu Kaushal, T. Shanmuganantham, "A Novel Microstrip Flower Patch Antenna Design for Multiband Operation", Journal of Materials Today: Elsevier, In Press.

[13] Deepanshu Kaushal, T. Shanmuganantham, "Microstrip Slotted Caterpillar Patch Antenna for S, Ku and K-Band Applications", Journal of Materials Today: Elsevier, In Press.

[14] Deepanshu Kaushal, T. Shanmuganantham, "Hex Band Microstrip Envelope Patch Antenna for Multiple Applications", Indian Journal of Innovations and Development, 5(11), pp.1-5, November 2016.

[15] Sheikh Dobir Hossain, K.M. Abdus Sobahan, Md. Khalid Hossain, Md. Masud Ahamed Akash, Rebeka Sultana, Md. Masum Billah, "A Rectangular Microstrip Patch Antenna for Wireless Communications Operates in Dual Band", International Journal of Wireless and Microwave Technologies (IJWMT), Vol. 6, Iss. 5, 2016.

[16] Nitika Mittal, Rajesh Mittal, Jaswinder Kaur, "Performance Improvement of U-Slot Microstrip Patch Antenna for RF Portable Devices using Electromagnetic Band Gap and Defected Ground Structure", International Journal of Wireless and Microwave Technologies (IJWMT), Vol. 6, Iss. 3, 2016.

[17] Deepanshu Kaushal, T. Shanmuganantham, "Comparative Analysis of Microstrip Moody Patch Antenna for Space Applications", IEEE International Conference on Electromagnetic Interference and Compatibility (INCEMIC), 2016.

\section{Authors' Profiles}

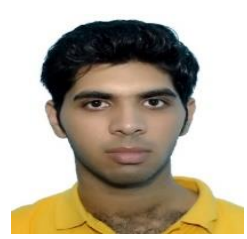

Deepanshu Kaushal completed his B. Tech. in Electronics \& Communication from Punjab Technical University in 2014. He is currently a IInd year M. Tech (E.C.E.) student of Pondicherry University and is doing his project on 'Microstrip Slotted Patch Antennas for Multiband Operation' under the guidance of Dr. T. Shanmuganantham (Assistant Professor, Department of Electronics Engineering, Pondicherry University, Pondicherry). His area of interest includes Antennas, Fractals and Metamaterials. He has 19 conference papers and 9 journals till date.

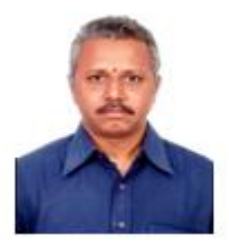

Dr. T. Shanmuganantham was awarded B.E. degree in Electronics \& Communication Engg from University of Madras in 1996, M.E. degree in Communication Systems from Madurai Kamaraj University in 2000 and Ph.D. (Received Gold Medal) in the field of Antennas from NIT (National Institute of Technology), Tiruchirappalli in 2010 under the guidance of Prof. S. Raghavan. He has 19 years of teaching experience in various reputed Engg colleges and currently he is working as Asst. Prof. in the Dept of Electronics Engg, School of Engg \& Technology, Pondicherry Central University, Puducherry. His research area of interest 
includes MEMS/NEMS, Microwave/Millimetre-Wave Engineering, Antennas. He has published 215 research papers in various National and International Level Journals and Conferences. He has completed two sponsored projects. He has been elected as Fellow in Antenna Test and Measurement Society (ATMS) and a senior member in IEEE, Life Member in ISSS, IETE, IE (India), CSI (India), Society of ISTE, EMC, ILA, OSI and ISI. He is serving as office bearer for IEEE Circuits and Systems Society (India Chapter) and also he is Member of Board of Studies in Pondicherry University, University of Madras, and Annamalai University. His biography was incorporated in 'Marquis who is who in the world' USA in 2010.

How to cite this paper: Deepanshu Kaushal, T. Shanmuganantham," Improved Performance Characteristics Using Double Layer Stacked Microstrip Loop Shaped Patch Structures for X-Band Operation", International Journal of Wireless and Microwave Technologies(IJWMT), Vol.8, No.1, pp. 14-24, 2018.DOI: 10.5815/ijwmt.2018.01.02 